\title{
LOS RECUERDOS FAMILIARES \\ DE LAMBERT DE WATTRELOS: TRES GENERACIONES DE HOMBRES EN UNA GENEALOGĪA FEUDAL
}

\author{
J.E. Ruiz Doménec
}

Una inquietud, mejor una obsesión, afligió a Lambert de Wattrelos entre 1152-1153 mientras redactaba una obra histórica a la manera del siglo XII denominada Annales Cameracenses ${ }^{1}$. Al llegar a 1108 , año de su propio nacimiento ( $₫$ Hoc anno natus sum infra terminum paschae et pentecostes»), deseó recordar el pasado de su propia familia que señoreaba desde hacía tres generaciones en el pagus Tornacense con un guante de hierro, feudalmente. Este testimonio personal es de suma importancia. Así se ha considerado desde hace algunos años. Lambert había pasado mucho tiempo en los scriptoria de Saint-Aubert de Cambrai donde llegó a ser canónigo e hizo importantes esfuerzos por expresarse bien, con cuidado. Los libros que leía continuamente aumentaron su desasosiego. Cada insinuación, cualquier relato fue un argumento más para incitarle a mirar en el fondo de sí mismo, recurrir a su memoria personal para aprehender la naturaleza de las cosas. Su obsesión excitaba' con fuerza la búsqueda de una precisión sobre el pasado familiar. Las nociones más sencillas, que él comprendía, eran enigmas para otros. Se preocupó ostensiblemente por el rango y por el valor de su linaje. En cierto modo, y como otros mu-

1 M.G.H. SS, t. XVI, 1859, pp. 509-554. Cfr. F. VERCAUTEREN, «Une parentèle dans la France du Nord aux XI ${ }^{\circ}$ et XII siècless en Le Moyen Age, 1963. pp. 223-245. Y G. DuBY, «La noblesse dans la France médiévale. Une enquête à poursuivres en Hommes et Structures du Moyen Áge, París 1973, pp. 145-166. 
chos hombres de su generación, experimentó una especie de revolución moral. La remodelación del pasado, impulsada por las casas monárquicas, afectó al núcleo de la memoria de los feudales². Lambert de Wattrelos sintió la necesidad de ser puro y limpio en la presentación de sus recuerdos familiares: esta ingenuidad le condujo a no apoyarse en investigaciones ni en documentos para probar el contenido de sus recuerdos ${ }^{3}$. De otra forma no se presentarían dudas y vacilaciones a la hora de explicar su contenido. Este relato genealógico lleva a cabo una vigorosa interpretación del sistema de parentesco feudal y, como será habitual más tarde en la literatura de evasión, se detiene en la generación de sus abuelos sin que exista ningún indicio de querer extender la memoria más allá. Así pues, los recuerdos familiares de Lambert de Wattrelos hablan de tres generaciones de hombres, entendidas como la verdadera y genuina egenealogia antecessorum parentum meorums 4 .

La mente de este canónigo se llena de fantasmas del pasado. Êl vive retirado del asiglo», en medio de la calma monástica: voluntariamente ha abandonado las tareas seculares. Pero con todo se preocupa de su familia. La enumeración de sus parientes es singular: los hombres ocupan en la memoria familiar un lugar clara. mente preponderante. Sólo diecinueve mujeres entre los setenta y tres individuos evocados ${ }^{3}$. Eso facilita la comprensión de los roles sociales que plantea la obra y desliza al lector a pensar cuál era la naturaleza exacta de aquello que hizo vibrar su mente con ideas y sentimientos extraños. Lambert no comprendió -o quizá no lo dejó escrito como hiciera su colega Guislebert de Mons unos años más tarde - que tales sentimientos eran sencillamente de amor"; él pensaba que era mera curiosidad por unos hombres - y más secundariamente por algunas mujeres - , que en el interior de su familia tenían diversas y grandes cualidades en potencia, y que el

2 J.E. RUIz DOMÉnEC, La memoria de los feudales, Barcelona, Argot, 1984.

3 G. DUBY. *Structures de parenté et noblesse dans la France du Nord aux XI" et XII siècles» en Hommes el Structures, op. cit., Pp. 267-285, espec, p. 269.

4 M.G.H. SS, t. XVI, p. 512. Cfr. R. How ARD BioCH. Etymologies and Genealogies. A Literary Anthropology of the French Middle Ages, Chicago 1983. p. 80. G.M. SPIEGEL, «Genealogy: Form and Function in Medieval Historical Narratjues en History and Theory, vol. XXII, núm, 1, 1983.

5 G. DUBY, Structures de parenté, op. cit., p. 273.

${ }^{6} \mathrm{G}$. DUBY, Que sait-on de l'amour en France au XIr siècle?, Oxford, Clarendon-Press 1983. 
suyo eta tan sólo una extensión personal de un pensamiento histórico. Evidentemente, Lambert se engañaba. Las relaciones entre los miembros de su linaje y el impulso evocador son justamente un fenómeno amoroso, una obsesión del alma que impulsaba como nunca se había hecho otra cosa y que le hacía comprender la razón de haber nacido en el interior de un sistema social específi$\mathrm{co}$, que nosotros, los historiadores, denominamos impropiamente la feudalidad.

Al observar de cerca la realidad del sistema de parentesco donde él nació y vivió hasta su retiro monástico, sus recuerdos se hacen más atrevidos. Lambert revivió toda la delicada trama social que forjó el feudalismo en las tierras de Europa cuando se conjuntaron los valores de la filiación (que eran administrativos y jerárquicos) con los de la alianza (que eran políticos y económicos) 7 . Miraba su pasado y lo deseaba con auténtica obsesión. Pero no había nada extraño en el interior de ese deseo, de ese amor, pues para êl sus familiares eran seres que le pertenecian, que formaban parte de su intimidad, de su «privacidad . La sustancia de las relaciones entre ellos (los diversos modos de alianza matrimonial presentes en el interior de esta noble familia) eran el resultado de un deseo por forjar un orden social nuevo y revolucionario. Si Lambert recordaba con tanta pasión esas cosas era por la devoción y el fervor que todo feudal ienía de sus antepasados. Quizá por ello mismo, no se daba cuenta de la confusión de valores que se operaba en su época, como no se daba cuenta de que el amor en el sentido feudal comenzaba a estar prohibido en el interior del universo monárquico y cortesano. No sabía que su mirada ardiente y viril sobre el pasado de su familia chocaba con las modas del momento hasta el punto de no darse cuenta de que sus recuerdos llegarian a perturbar el curso de los razonamientos políticos y forzarian a discurrir sobre cosas que en este momento iban a ser elididas. Lambert habla con facilidad y su discurso es diáfano, cosa rarisima en esta época (sobre el año 1152) donde lo propio del sistema cultural era dar actualización a la memoria para adaptarla al servicio de los principes. Poco sensible a las presiones exteriores, el contenido de su memoria es, en sentido estricto, el resultado de un esfuerzo por comprender la realidad del sistema de parentesco feudal.

El problema histórico ( $y$ naturalmente antropológico) suscitado

7 J.E, Ruiz DOMÉNEC, L'estructura feudal, Barcelona, Llibres del Mall, 1985. 
en este momento consiste en saber hasta qué punto Lambert es preciso en sus recuerdos - en especial en aquéllos que se refieren a la terminología del parentesco. Tres importantes conceptos aparecen en la evocación de los hombres de su familia: el de cognatus, el de consanguineus, el de avunculus. De los tres, dos de ellos (cognatus y consanguineus) han recibido una interpretación a mi juicio equivocada por parte de F. Vercauteren, lo que ha encaminado el análisis de la memoria de Lambert en una dirección errónea. Este autor tradujo cognatus por sobrino, cuando en realidad es el concepto que hace referencia al hermano de la esposa y consanguineus por pariente a secas, cuando casi con toda probabilidad se refiere al primo cruzado matrilateral ${ }^{8}$.

Con tales interpretaciones, la situación familiar de Lambert quedó muy confusa. El esquema mental surgido de su imaginación (basado en el principio de las tres generaciones, cuyo valor es intenso como luego veremos) se diluía, al mismo tiempo que no se encontraba ningún indicio sobre la ley de selección del parentesco que rigió la feudalidad occidental al menos hasta finales del siglo XII.

Así pues, analizado en profundidad el testimonio de Lambert de Wattrelos relativo a los vínculos, particularmente estrechos, que existen entre los miembros alejados, en la generación de sus abuelos, es decir, las relaciones de alianza, filiación y consaguinidad fijadas entre su abuelo paterno y su cognatus y su abuelo materno y su consanguineus, que, cosa importante, es el mismo individuo, se llega a un sistema de parentesco cerrado en tres generaciones contadas desde el Ego (no cuatro según se deduce de la interpretación de Vercauteren) que relata el propio Lambert, según podemos observar en la figura 1:

Esta es la genealogía de los antepasados de Lambert, de acuerdo con la lectura que hago de la terminología de parentesco que el propio Ego cita como testimonio. Conviene, no obstante, dete-

8 F. VERCAUTEREN, op. cit., P. 230.

9 Existe, no obstante, una indecisión en el trabajo de F, Vercauteren, por cuanto en la p. 229 habla que $₫$ De cette famille Lambert va nous donner une description et una généalogie qui s'étendent sur trois gếnérations c'est-à-dire, en fait, sur un siècles; y más adelante introduce a ese Everardus en la cuarta generación contada desde Lambert. Mi lectura genealógica deberá ser contrastada con la ofrecida por este autor, op. cit., pp. 233 y 239. 


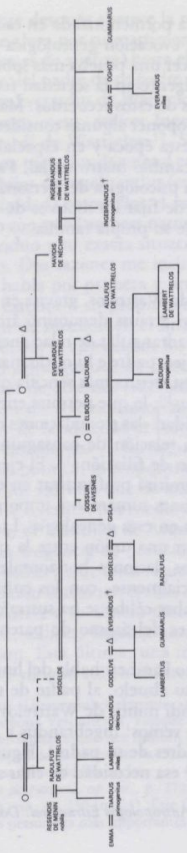

혼 
nerse de una manera pormenorizada en cada uno de los momentos cruciales de esta evocación genealógica con un triple fin: primeramente, establecer una prueba más sobre la realidad del sistema de parentesco vigente en la sociedad feudal, de acuerdo a los principios emanados de estos recuerdos. Más adelante, y de forma complementaria, proponer algunas consideraciones sobre los roles de clasificación de esta época y en especial sobre el papel de las mujeres en el intercambio matrimonial. Para, finalmente, penetrar en la naturaleza psicológica del personaje que recuerda con la intención inter alia de fijar los motivos de esta necesidad de memorizar el pasado de su propia familia.

El Ego, Lambert de Wattrelos, gravita en el interior de un sistema que Claude Levi-Strauss denominó átomo de parentesco, es decit, un sistema cuadrangular de relaciones entre hermano y hermana, marido y mujer, padre e hijo, tio materno y sobrino que es, en cierto modo, la estructura más sencilla que sea dado concebir y a veces hasta observar ${ }^{10}$; lo que permite entre otros muchos aspectos percibir con claridad alas tres relaciones consecutivas del parenresco, es decir, una relación de consaguinidad, una relación de alianza, una relación de filiación" ". El ejemplo de la genealogía de Lambert nos permitirá profundizar en esta dirección y extraer algunas consideraciones sumamente importantes.

Tal como aparece en esta genealogía, Lambert observa a su familia constituida por una unión entre la rama paterna y la rama materna, junto a las ilaciones horizontales con sus hermanos y hermanas $\mathrm{y}$, potencialmente, con los cuñados de sus hermanos (pues al ser un hombre célibe se ha sustraído voluntariamente de una de las relaciones del átomo de parentesco, la de marido y mujer).

En primer término Lambert habla del linaje paterno. Se remonta de inmediato a su abuelo, al padre de su padre: «Pater siquidem meus Ingebrandi militis de Wattrelos et Havidis de Nethim filius extitit». Ya lo vemos: Ingebrandus y Havidis, sus dos abuelos paternos (los padres de su padre). Figuras ambas de gran im. portancia. ¿Por qué esa necesidad de citar aquí el nombre de una

$10 \mathrm{Cl}$. LeVI.Strauss, Antropología Estructural. Dos, México 1973, p. 83.

11 Ibidem, p. 83. 
mujer? Inmediatamente después aparece la razón, este Ingebrandus miles et casatus se eleva por su matrimonio con Havidis (cristalización de las relaciones de alianza) hasta el punto de que el pariente más importante del padre de su padre es justamente el hermano de su esposa: ese Everardus de Wattrelos que es cognatus de Ingebrandus: «Avus vero meus, scilicet Ingebrandus de Wattrelos, fuit cognatus Evrardi de Wattrelos» ${ }^{12}$. Si mi hipótesis es correcta, Everardus es una picza fundamental en el sistema, pues será tío materno de los hijos de Ingebrandus (cristalización de las relaciones de consanguinidad) entre ellos el padre del mismo Ego. Eso explica el cuidado con que Lambert narra el propio destino de este importante individuo y su exacta situación en el interior del sistema de parentesco. Dos razones me inclinan a pensar así. En primer lugar, el Ego habla por primera y única vez de un matrimonio «exogámico», exterior a su propia familia. Necesita dar a conocer como el orden de sucesión en el linaje de Wattrelos cayó en la línea de su padre, por la ausencia de los hijos de Everardo. El buen matrimonio del primogenitus de Everardo, Elbodono, con la hermana de Gossuin de Avesnes ( Elboldo vero primogenitus duxit uxorem Gossuini de Avesnes sororems), un linaje situado en oun grado superior de la sociedad aristocrática, los señores de Avesnes, familia de castellanos ${ }^{13}$. En segundo lugar, y dentro de una perspectiva más política, más oportunista ${ }^{14}$, esta evocación le permitía establecer los vínculos que de antiguo ligaban a su familia con los señores de Avesnes, por medio de esta mujer que era tía materna (matertera) de Gauthier de Avesnes, denominado Puluchet. Concluida esta exigencia de precisión que sin duda es el punto más oscuro y conflictivo de estos recuerdos familiares, Lambert prosigue su evocación con el tercer tipo de relaciones, las propiamente filiativas. Vuelve a su abuelo paterno Ingebrandus que qquatuor filios habuit, scilicet, Ingebrandum, Oghot, Gummarum. Alulfum et filiam. Esta última, una mujer que no nombra (posiblemente no tuvo ningún rol en el intercambio matrimonial

12 Se podría suponer que al llevar ambos el mismo apellido debe significar una relación filiativa, según supone Vercauteren, aunque tenemos suficientes datos de archivo de otros linajes feudales que nos indican que parientes por alianza también llevan el mismo apellido. En esta misma Geneaología sin it más lejos, el abuelo materno también se llama de Watuelos.

13 G. DuBY. Structures de parentê, op. cit., p. 272.

14 F. Vercauteren, op, cif., p. 230 (n, 23). Este Gautier de Avesnes murió en 1147, y era uno de los personajes más importantes de la región. 
y, por tanto, carecía de valor social). De ese modo llega a su padre, Alulfus aquasi omnium ultimus». ¿EL último de vedad? El padre tuvo la mejor suerte de todos, pues tomó (duxit) en matrimonio «filiam Radulfi de Wattrelos nomine Gislam» ${ }^{15}$, y además tuvo una larga descendencia: *ex qua nati sunt sex filii et quatuor filiae». El hijo no escatima elogios para esa mujer, su madre, llena de gracia, fecunda, al servicio del linaje, que como toda esposa perfecta es sumisa y está dispuesta a la procreación de hijos para mantener las relaciones de filiación y de hijas para fortalecer las relaciones de alianza. Pero además esta Gisla, hija de Radulfo de Wattrelos, conecta a los hombres de su grupo de filiación (aquí el carácter patrilineal y agnático de la sociedad feudal pesa lo suyo) con la otra rama, la superior, la más importante, de donde vino esa ejemplar mujer ${ }^{16}$.

El linaje materno es más complejo. Lambert habla también aquí en primer lugar de su abuelo «Radulfus, avus meus, pater scilicet matris mee». Fórmula habitual, pero importante: en el interior del sistema feudal, todo aristócrata podía tener descendencia por dos líneas, la de los hijos, la de las hijas. El abuelo materno fue un hombre riquísimo (vir ditissimus). Este recuerdo le sirve para ponderar el exacto valor social de la riqueza (divitae). Lambert espontáneamente imaginó que esta situación de superioridad económica ( ¿acaso no de rango?) de su abuelo Radulfo simbolizaba la vitalidad, la prosperidad que vivió el distrito de Tournai durante estos años. Seguro de su observación retrospectiva, confiaba que este argumento fuera suficiente para establecer correctamente el orden en el interior de su linaje. Pero tampoco aquí supo cómo situar el tema del amor, feudalmente considerado, es decir, la elisión de los aspectos «negativos» de la relación hermano/her$\operatorname{mana}^{17}$.

Consideremos este asunto desde el punto de vista de quien ha-

is Obsérvesę como he indicado más arriba la aparición de nuevo del apellido Wattrelos, alejado de la línea filiativa paterna de Lambert. Síntoma de que nos encontramos ante una estructura de parentesco mucho más cerrada de lo que se ha supuesto hasta este momento.

16 Lambert de Wattrelos dedica a su madre un bello epitafio poético el año de su muerte (1145) inscrito también en el interior de los Annales Cameracenses, op. cit., P. 516.

$17 \mathrm{Cfr}$. Cl. Levi-Strauss, op. cit., pp. 83 y ss. M. Douglas, Simbolos naturales. Exploraciones en cosmología, Madrid 1970. G. Deleuze, F. Guattari. L'anti-oedipe, París, Minuit 1972, Pp. 180 y ss. 
bla: de Lambert de Wattrelos, nieto de aquellos individuos que fijaron los pactos. La dificultad mayor de la evocación de este canónigo consiste en la siguiente expresión referente a su abuelo materno: «Radulfus... consanguineus Everardo memorato.» ¿Qué significado tiene aquí el concepto consanguineus? Se ha dicho que ningún valor consecutivo: simplemente es un vocablo que define a un pariente lejano $^{18}$. Por el contrario estimo - asentado en la gran experiencia de otros muchos casos plenamente documentados- que este concepto se refiere al primo cruzado matrilateral, que además en muchas ocasiones se convertía en el esposo de la hermana. ¿Fue realmente así en este caso? De hecho la feudalidad se caracterizó entre otras muchas cosas por un deseo de crear un ámbito social y un sistema de articulación basado en la alianza matrimonial entre primos cruzados. La ruptura de estas regulaciones condujo a la anomia, e incluso su duda supuso el desamor como puede comprobarse en la literatura épicali". Las relaciones sociales feudales exigen que Radulfo entregue a su hermana en un sentido descendente a uno de los hombres proximi, a alguno de sus parientes cercanos, a sus consanguinei. El orden feudal se asentó en esta estructura que fue una exigencia básica para los grupos dominantes. Pero Lambert habla con dificultad de estos temas. Obsérvese cómo enumera a las hermanas de su abuelo materno: $«$ Radulfus scilicet avus meus habuit nempe et sorores quae maritate fuerunt.... Nempe: por supuesto, naturalmente. Algo irremediable sobre lo que hay que hablar. Pero poco más. Este canónigo había llegado a la conclusión durante su larga vida monástica de que sobre estos asuntos era mejor no ser muy claro. Esto le sirvió para dar una imagen moralmente aceptable para los ojos de su época. Pero Lambert capta la situación extraña, el momento peligroso, oscuro, donde los recuerdos familiares se deslizan insensiblemente hacia la evocación de esas prácticas matrimoniales, endogámicas, tan perseguidas por los moralistas de la Iglesia ${ }^{20}$. Entonces aprovecha la ocasión y juega su baza con toda energía y decisión. Olvida el problema, y no habla de amor. En su retiro no advirtió el cambio tan agudo que se daba por entonces a esa

18 F. VerCAUTEREN, op. cit., p. 235.

19 J.E. RuIz DOMENEC. Reowl de Cambrai. Reflexión sabre el desamor en la época feudal. Bellaterra, Monografias de Medievalia, núm. 4, 1984.

20 G. DuBY, Medieval Marriage. Two Models from Twelfib-Century France, Baltimore-London, 1973. 
misma noción, cuando se cargó de contenidos cortesanos y caballerescos.

Lambert prefiere volver la vista de nuevo al abuelo y a su matrimonio. Modifica los recuerdos para dar entrada a algo tranquilizador y a la vez estimulante: el buen matrimonio de la familia de Wattrelos con «nobilis Resendis». Ante todo esta mujer, la esposa de su abuelo materno, era «ab alto sanguine nobilium Flandrensium duxit originems: una buena cuna, un buen origen. Todo lo demás era secundario. Lambert de Wattrelos recuerda esta importante acción de su abuelo materno y se fija en la distancia social - de rango - que le separaba de ella, y que nunca supo como podría atravesar. Naturalmente necesitaba hablar de esta mujer: la abuela pertenecía a una clase más elevada que la de todos los hombres de la familia, era un ser único y aparte. Superior. Cierto que la clasificación de su abuela materna se lleva a cabo según la costumbre de la época, pues Lambert destaca en primer término y con fuerza la importancia de los siblings de su abuela: «ista quidem undecim fratres...», muchos de ellos «famosi milites» y otros *nobiliores de illorum sanguinitate». En la mente de este canónigo la importancia de su abuela venía por la importancia de los hombres que la rodeaban. Las cosas debían de encajar cada una en su sitio. Pero un día, esta mujer tan importante, tan elevada y rica, fue a parar a la casa de su abuelo materno. Bajó de grado social. Fue donada en sentido descendente según la ley del parentesco feudal. Por su importancia adujo al matrimonio un número elevado de esclavos (servi et ancillae) de carácter doméstico. El abuelo la recibió con interés. Después de todo, las relaciones feudales se afianzaban con decisiones de este tipo. Al momento desapareció la superioridad social de la mujer sobre el esposo, para fortalecer en lo posible el principio de la masculinidad tan omnipresente en esta sociedad. Sumisa, aceptó el destino que las reglas de la alianza matrimonial de la feudalidad tenía preparada para estas mujeres tan excepcionales, en sí mismas llenas de nobilitas.

Esta actitud plantea directamente muchos interrogantes sobre las relaciones existentes en la sociedad feudal entre los registros afectivos y la realidad social. Pero en cualquier caso, y como una simple consideración de la genealogía aquí analizada, puede verse cómo «en el esquema presentado por Lambert de Wattrelos, la rama materna es muy claramente la rama gloriosa ${ }^{21}$. Eso explica,

21 G. DuBY, Structures de parenté, p. 277. 
en mi opinión, varias dimensiones sobre las que Lambert insiste con sumo placer. Primeramente, el registro afectivo entre él y uno de los hermanos de su madre. Relación que se desdobla simplemente en la generación superior, la de los abuelos, donde la familia alcanzó eso que el Ego llama la nobilitas (una cuestión de sangre, no de riqueza ${ }^{22}$ ). Registros afectivos positivos que permiten, en segundo lugar, considerar la estructura total de sus recuerdos como la representación emotiva del orden feudal, en lugar de mutilar o reducir su arquitectura en función de forzadas interpretaciones de los conceptos de parentesco.

Los feudales se encontraron ante una evidencia altamente peligrosa: la estructura inicial que encauzó la revolución y forjó el orden feudal configuró al mismo tiempo un tipo original de filiación, un sistema aelementals de alianza matrimonial y un grado particular de consanguinidad. Las mujeres cumplieron un rol decisivo, pues en la mayoría de los casos, ¿no en todos?, ellas venían de un linaje más elevado, de mejor cuna, y permitieron conectar a sus descendientes con las familias de los príncipes. Todo esto es evidente. Está presente de un modo dramático en los recuerdos de Lambert de Wattrelos. Pues, ¿cómo compaginar las realidades del pasado evocado y las presiones por parte del sistema social de su época $y$, naturalmente, aquellas otras presiones que están estrechamente relacionadas con su particular moralidad como miembro de una Iglesia reformada?

Lambert de Wattrelos retorna a la narración familiar: «Ad avos redeamuss. Cuando acaba con la evocación de las ramas alejadas, de esos famosos y eminentes hombres de buenísima sangre, tiene que volver, regresar, al punto de la narración donde genealógicamente todo comienza. El padre de su madre es una figura fundamental. No sólo conecta mediante un sistema de alianza con aquellos antepasados que no recuerda, sino que es el único que establece relaciones de parentesco con el recordado Everardo. El regreso a la primera generación alcanzada por su memoria - la de sus abuelos - le permite profundizar en la realidad de la familia de su madre. Lambert poseía la mente de todo estudioso, y tras su capacidad de aprender se encontraba un carácter indomable y su

22 Véase el informe de K. Bost. Adel, en Frübformen der Gessellscbaft im mitrelalterfichen Europa. München-Wien 1964, pp. 220-227. El ideal nobiliario lo analiza H. KALFELZ, Das Standesethos des Adels im 10. und 11. Jahr. bundert, Würzburg, 1960. 
amor por el recurso familiar se exaltó al conectar con la parte más importante, más célebre. Se nota en el lenguaje, en el cuidado que tiene de citar a todos los hermanos de su madre y el destino - el importante destino - que les aguardaba en la gran política de su tiempo. Con gran alegría habla, pues, de su tío materno, el mayor, el primogénito del padre de su madre: «Tiardus primogenitus postea maior de Wattrelos fuit. Is uxorem honestam duxit Emmam nomines; alaba, pues, el buen matrimonio y, cosa natural, a continuación, la capacidad reproductora: «ex qua sunt orti milites et clericis. Dos vocablos llenos de intención social, que al ser conjugados pueden favorecer el destino de una sociedad en crisis, pues estas dos realidades en último término se definen por su idea del servicio a los grandes, a los nobles. Lambert fija la distancia social al establecer los rangos. Inmediatamente habla del segundo de los milites, hermanos de su madre, llamado Lambert, como él mismo. Este aventurado individuo, de nuevo un tío materno en funciones heroicas, su padre le envió ( transtulit») junto al rey Enrique I de Inglaterra. ¿No apostaba con esto por las orientaciones políticas de su momento en pleno conflicto entre el otro Enrique (II, nieto del anterior) y los descendientes de Esteban de Blois? La familia de Lambert apostó muy pronto por la casa angevina y su implantación en el trono inglés. El tío materno de nuestro Ego, Lambert, llevó una vida llena de privaciones, abnegada. Murió al servicio del rey en la guerra contra el conde de Flandes: «in prelio tamen, quod inter regem Angliae et Balduinum comitem Flandriae extitit, vulneratus fuit; ad ecclesiam tamen transfugit, et sic defunctus est». Eso obligó a que uno de los sobrinos, el mayor, Balduino, acudiera a la corte en su lugar: «Nam frater meus, Balduinus interfuit». ¿Qué quiere decir con ello? El relato aquí lo silencia. ¿Acaso porque Lambert de Wattrelos no conocía el resultado de esta estancia en la corte? ¿Qué pasó realmente?

Tras la evocación de los hermanos de su madre dedicados al ejercicio de las armas (milites) llega a aquellos otros que se consagraron a Dios, que renunciaron al «siglo». ¿Es acaso este el orden adecuado, primero los laicos, luego los eclesiásticos? El recuerdo se concentra en un personaje fundamental, Ricuardus, vir bonae memoriae, tío materno de Lambert, quien le acogió en el monasterio cuando en 1115 , siendo él un niño y por decisión de su linaje, le ingresaron en él: ssed sabe arbitrio Ricuardi avunculi mei totum actum est, qui me iacentem adhuc in cunis a matre mea si- 
bi dari postuleverat, auge fuit eiusdem germanas. Se advierte en seguida que Lambert ve a su tío materno Ricuardo de una forma abiertamente positiva. Los registros afectivos muy cautelosos para su padre, o sus hermanas, son cordiales y espontáneos con su tío materno. No hay desconfianza ni distancia con respecto a este hombre, a quien los jóvenes acudían para pedirle favores: en el sector laico, la búsqueda de una esposa, en el sector eclesiástico, que le introdujese en los laberínticos procesos culturales del universo monástico. Las normas feudales una vez más traspasaron los muros de los conventos y penetraron en el interior de un mundo reglamentado según otros principios. ¿Pero podían estos monjes olvidar tan fácilmente los principios estructurales que regían en el seno de su familia, y que habían aprendido desde la infancia? La positiva relación de Lambert y su tío materno habla en favor del porvenir de estos registros afectivos dentro del mundo monástico.

Los recuerdos de Lambert de Wattrelos plantean muchos problemas subsidiarios. El primero de ellos se refiere a las complejas referencias al sistema de clasificación social inscrito en la memoria. El concepto nobilis aparece una sola vez y en relación a la abuela materna. La narración en ese plano alcanza cotas claramente literarias, cuyo impulso consiste en reafirmar el carácter legendario, épico, de algunos antepasados: aquellos sobre los que acantilenam mimorum recitantur ${ }^{23}$. Lambert es intensamente feliz en estas descripciones como se comprueba en el calor con el que describe la alta cuna de su abuela materna o los lazos de sangre que conectan con las familias más poderosas de la región. La alegría de saberse asuperiors, inscrita en las normas de la alianza matrimonial de la feudalidad occidental, la disfruta como un hecho social total. El ambiente que circunda esta descripción, los gestos de soberanía que se entreveen en este preciso momento, parecen la confirmación de un modo de clasificación coherente y seguro. Esa era la verdadera existencia de los grupos dominantes y los que escribían, como este canónigo, lo llevaban en su realidad interior.

¿Pero por qué sólo la abuela materna es nobilis? Naturalmente una definición de este tipo hace referencia directa al carácter del

${ }^{23}$ Cfr. G. DuBy, Structures de parenté, op. cit., p. 277. 
matrimonio vigente en el sistema feudal y a esa particularidad de ser los feudales verdaderos adonadores» de mujeres. La abuela Resendis viene de más alto y de más lejos (como ocurre con Aalais en el Raoul de Cambrai). ¿Es una princesa? ¿Por qué el padre de su madre tuvo acceso a una mujer de este tipo? ¿Se repetirá ese caso? ¿Cuál es el destino de Balduino, el hermano de Lambert, cuando acudió a la corte? ¿Acaso este intrépido joven de la tercera generación de la familia de los Wattrelos buscaba una mujer de rango superior, ansiaba una princesa?

La memoria de los feudales se llena de intensidad cuando se recuerdan actos como la presencia de nobilis Resendis en el interior del sistema de parentesco que se extiende en la misma generación a un miles cassati del obispo de Cambrai. ¿Acaso es que la nobleza se trasmite por vía materna, como se ha sugerido en ocasiones? ${ }^{24}$. No se trata de eso. Simplemente que el matrimonio preferencial y el intercambio generalizado consistía en la cesión de una mujer de los grupos superiores a los grupos inferiores. La presencia de Resendis no se explica por razones de filiación sino de alianza matrimonial. Naturalmente en un sistema como este, los hermanos de las esposas (que vienen de más arriba) adquieren un papel fundamental. Lambert comprendía esta dimensión de las cosas, por eso concede más importancia y más espacio a los recuerdos de la familia de su madre. Era naturalmente de un rango superior a la de su padre. Esto consolaba, en cierto modo, pues el recuerdo de sus antepasados ilustres le conducía a presentar al mismo tiempo al padre de su padre y al padre de su madre. Al fin de un proceso, en la tercera generación, las ramas se conectaban y la sangre de una nobilis corría por las venas del descendiente de uno de los siervos casatus del obispo de Cambrai. La movilidad vertical de esta sociedad se encauza por el carácter del matrimonio feudal.

Pero la abuela Resendis era una mujer después de todo. Lam. bert se dio cuenta repentina y fue una revelación que le dejó atónito. Era como si la venda se hubiera desprendido de sus ojos tanto tiempo taponados en el refugio monástico. Los recuerdos aquí analizados ponen en evidencia lo que significaba para una socie-

24 Suscitada por L. VERRIEST, Noblesse, chevalerie, lignage, Bruxelles 1959. Para un estado de la cuestión del problema véase T. REuTER, The Medieval Nobi. lity. Amsterdam 1978 (introduction, pp. 1-16). También C.B. BOUCHARD, \&The Origins of the French Nobility: A Reassessments en American Historical Review, 86,1981 , núm. 7, pp. 501.532. 
dad dominada por el hombre, masculina, que la mujer fuera de un rango superior. El escándalo debió de ser extraordinario. Lambert tembló ante la audacia de un pensamiento que destacaba los elementos de esa superioridad, fijada en los valores estructurales del parentesco. ¿Qué cosa hacer? O mejor aún, ¿qué tiene que ver todo esto con que en estas fechas, hacia 1152, hombres como Lambert comenzaran a recordar?

El hecho de que Lambert de Wattrelos no fuese un escritor profesional al servicio de un señor laico y pagado por él para componer un escrito genealógico sobre una familia, no disminuye el valor de su testimonio. Al contrario, lo hace más intenso, más personal. Durante la corta evocación de la familia Wattrelos, este canónigo se dedicó a un profundo análisis de sí mismo e introdujo algunos datos que aumentan considerablemente el conocimiento que tenemos del sistema de parentesco feudal.

Este plano de los recuerdos personales e íntimos, no profesionales, tiene una dimensión particular e inquietante: ¿por qué todas sus evocaciones se detienen en la tercera generación? Lambert no traspasó nunca esa línea imaginaria de los abuelos. ¿Acaso se trata de una escasa memoria de los antepasados? ¿Falla la mente y al no recurrir a los documentos no puede avanzar más allá de la generación de los padres de sus padres? ¿Qué hay de realidad en este caso tan repetidamente expuesto en la memoria de los feudales? Este asunto no es nada fácil. Las probabilidades de ofrecer una explicación satisfactoria a este extraño, y a la vez generalizado, giro en los escritores genealógicos son remotísimas ${ }^{25}$. Es posible introducirse en las formas de pensar de un individuo de hace más de ochocientos años y buscar una explicaciōn razonada de su actuación? Otros incluso se preguntarían si una indagación de este tipo es necesaria para el saber histórico ${ }^{26}$. Tal vez sea esta serie de dificultades superpuestas la causa de que aún desconozcamos muchos

2s Me refiero naturalmente a los recuerdos rgenealógicoss no realizados de una forma intencionada y sprofesionals, como Lambert de Ardres que habla de ocho generaciones. Cfr. G. DUBY. Structures de parenté, op. cit., pp. 278 y ss. J.E. RUIz DOMENEC, Lo memoria de los feudales, op. cit.

${ }^{26} \mathrm{Cfr}$. H. WHITE, eThe question of Narrative in Contemporary Historical Theorys en History and Theory, vol. XXIII, núm. 1, 1984, pp. 1-33. 
aspectos importantísimos de la forma de pensar y de ser de los feudales. En pocas palabras, ¿qué indujo a Lambert de Wattrelos a detenerse en la generación de sus abuelos al redactar la memoria de sus antepasados?

Primeramente, para este escritor monástico, los recuerdos de su familia constituían una especie de liberación de un extraño fantasma personal y cultural. El orden imaginario era un premio suficiente para su esfuerzo memorístico. Pero más que el orden, Lambert se cuidaba de la moral. Consideraba que la moral de la Iglesia reformada era la cosa más grande y elevada del mundo. Era esa moral la que había transformado a los rudos feudales y les empujaba a convertirse en buenos caballeros al servicio de Dios ${ }^{27}$. En medio del ejercicio memorístico, Lambert descubrió también que de ese modo su cerebro se liberaba de tensiones oscuras y peligrosas. ¿Qué ocurría en la cultura europea hacia 1150 para que las cosas alcanzaran una dimensión semejante?

Ciertos indicios, algunas observaciones generales, permiten suponer que, pasado el año 1150 , al mismo tiempo que la literatura levantaba el velo de muchas cosas ocultas, una aguda alteración afectó el contenido social de la feudalidad y la condujo a una profunda crisis. Los escritores de la época entendieron todo esto con especial intensidad, pero no aflojaron su interés por la moral eclesiástica. Lambert, como otros muchos, trabajó con entusiasmo para mantener la moral al margen de la catástrofe que se avecinaba. La tragedia se convirtió en el telón de fondo donde se inscribieron la mayoría de estos desgarrados comportamientos. Resultó imposible escapar del aciago destino de los rudos aristócratas feudales sin hacer una serie de giros asombrosos en el orden social y político, y, desde luego, tal recorrido no pudo realizarse sin una orientación clara por parte de la Iglesia, que era quien, en definitiva, tenía la mayor responsabilidad en el asunto.

Dos obras literarias de este período plantean el problema con esa especial y laberíntica propensión a enmascarar las cosas que tienen las obras de creación. La primera, el Roman de Thèbes, analiza brillante y profundamente el comportamiento de Ethyocles y Pollynnices, hijos del hijo de Layus, ante un suceso oscuro e inquietante, que afectó al núcleo de su familia ${ }^{28}$. Esta obra, inspi-

27 J.E. Ruiz DOMf́nec, La caballería o la imagen cortesana del mundo, Génova, Istituto de Medievistica (Collana Storica di Fonti e Studi), 1984.

${ }^{28}$ Le Roman de Thëbes, ed. G. RAYNAUD DE LAGE, París 1969. Sobre el am. 
rada lejanamente en los modelos clásicos, formó la costumbre de hacerse una idea sobre esa cuestión, de madurarla debidamente y de asumirla por parte de un público compuesto en su mayoría por familias como la descrita por Lambert de Wattrelos. La audición de un roman como éste supone el acto culminante de un largo proceso mental, la reunión y armonización creadora de todo un conjunto de pensamientos e interrogantes y la generalización final sobre un fondo alejanos - la época clásica - que facilitaba las cosas y tranquilizaba al auditorio. Pero la obra acoge en su seno las altas preocupaciones de la Iglesia y la necesidad de encauzar la conducta de los laicos. El trágico suceso por el que los nietos de $\mathrm{La}$ yus se ven abocados a la errancia es un oscuro fantasma que preocupaba hondamente a la sociedad sobre el 1150. ¿Qué fantasma era ese?

Unos años más tarde - pero con seguridad antes de 1182 - un escritor cercano al mundo de la corte capeta, instigado por la fuerte corriente de los moralistas de París, describe tambiên en tres generaciones las desgracias de una familia muy noble. Este individuo, Gautier, no comprendió muy bien los motivos de la muerte del hermano de su madre, su tío materno, un paranoico exaltado que da nombre a la obra, llamado Raoul de Cambrai ${ }^{29}$. Guerras, agresiones, turbulencias, desencadenaron un estado de caída y de destrucción, y también la sombra de ese fantasma que aprisionaba la conciencia de los feudales. ¿Qué fantasma era ese?

Estas obras constituyen un esfuerzo consciente por liberar a la sociedad de una angustia que pesaba en el interior de la conciencia de los aristócratas feudales. Una forma completa de «desahogos que les indujo a decir la última palabra sobre un dolor real e imaginario para olvidarse de él. La muerte del padre (o la del tío materno, que en un registro afectivo es idéntica ${ }^{30}$ ) da lugar al fantasma de la reversión de las generaciones ${ }^{31}$, donde la relación hijo/abuelo es correlativa a la de hijo/padre-idealizado, lo que permite al Ego una respuesta mediatizada, inscrita en una dimensión cultural, objetiva ${ }^{32}$. En este sentido, y aquí se inserta la tesis

biente literario de estas obras, cfr. G. ANGEL, $L$ ' Eneass e i primi romanzi volga$r i$, Milano 1971 , espec. Pp. 60-69.

${ }_{29}$ Cfr. J.E. RUIZ DOMENEC. Raoul de Cambrai, op. cit.

30 Cl. Levi-Strauss, op cit., p. 87.

31 E. JONES, Papers on Psychoanalysis, Boston 1961, pp. 407-412.

32 G. Rosolato. Essais sur le symbolique, París 1969, pp. 74 y ss. 
que quiero desarrollar, la necesidad por parte de un Ego de escribir una genealogía de sus antepasados - tal como lo hace Lambert de Wattrelos- es el resultado de un impulso provocado por el fantasma de la reversión de las generaciones, que es la consecuencia, a su vez, de la terrible constatación de la muerte del padre y la total exigencia de huir imaginariamente ante el complejo de Edipo. Este impulso necesita una estructura organizada en tres generaciones de hombres, para poder entender la proyección del problema en el plano superior, donde el padre (o, naturalmente, el tío materno) conecta con su propio padre: abuelos ambos del Ego.

Este es el núcleo de la preócupación de los feudales en este momento histórico, sobre 1150 , y es el fondo de la obsesión de Lambert de Wattrelos, pues, psicológicamente hablando, la genealogía es una idealización del padre y un modo sustitutivo de alcanzar pleno conocimiento del yo ${ }^{33}$. Lambert, como todo feudal en este momento, se pregunta por los registros afectivos que se establecieron entre los miembros de su familia, sus padres (y sus tíos maternos) en relación a los suyos propios: de ahí la necesidad de estructurar los recuerdos en un átomo de parentesco donde aparecen plenamente definidas las relaciones cuadrangulares ya citadas. La pieza fundamental de estos recuerdos es Everardo, cognatus del padre de su padre, consanguineus, del padre de su tío materno: filiación, alianza, consanguinidad, tres dimensiones, tres hombres ligados entre sí por un sistema de parentesco que genera un orden y un lenguaje.

De repente el fantasma desaparece. La elisión del papel fecundador del padre asegura el rol del ancestro importante (los dos abuelos y el pariente que los une), de modo que el conjunto de la sociedad emerge así como el reultado de una decisión tomada en un momento, fuera del control temporal cotidiano, que se entiende como festivo e inicial jara la familia. La relación entre el padre y la madre del Ego se neutraliza mediante el impulso de evitar que los otros vieran ese detalle íntimo, privado. La genealogía oculta el episodio terrible en la vida de un hijo, el coito entre su padre y su madre. Lambert mediante este juego - que creó una teología en los pueblos indoeuropeos si creemos los estudios de Georges Dumèzil- supera el secreto original, psicológicamente

33 S. FreUD, «Remarques psychanalytiques sur l'autobiographie d'un cas de paranoia (Le Président Schreber)y en Cing Psychanalyses, París 1954. 
traumatizante, y recurre a la memoria genealógica como un olvido superior: un olvido que conduce a la búsqueda del origen absoluto y subsidiariamente a las creaciones culturales, como, por ejemplo, la literatura cortesana ${ }^{34}$.

Así pues, la necesidad de una Untergang del complejo de Edipo obligó a los feudales a forjar un tipo peculiar de recuerdo, el propiamente genealógico. Una solución a las obsesiones que desarrolla la literatura a partir de entonces y de un modo inquietante. Los escritores buscaron afanosamente la forma de que no volviera a suceder nunca más. Las nuevas orientaciones morales disminuyeron los riesgos. La genealogía resolvió en un primer momento los problemas, por eso los feudales para recuperar el pasado se apoyaron en ella. Pero el hecho de haberse apartado abiertamente del orden feudal al aparecer estas preocupaciones llevó a traicionar la explicación coherente y natural de su origen.

¿Qué pasó entonces? El tiempo destruye el sistema forjado en un momento inicial: esa es la terrible constatación. El padre del padre del Ego y el padre del tío materno del Ego (los dos abuelos) mueren. Eso era inevitable. ¿Cómo lo hicieron? ¿Por qué lo hicieron? ¿Qué parte de culpa tuvieron los hijos en la muerte de los abuelos? Interrogantes imposibles. La memoria sustituye el desfallecimiento físico, pues, como sostiene Jacques Lacan, el nombre del padre debe ser invocado para facilitar la permanencia de la trasmisión genealógica.

La genealogía vence al fantasma feudal de cómo y por qué mueren, desaparecen, los creadores, los forjadores de un sistema. La vuelta cíclica del tiempo no era factible para los hombres. La memoria quiere fijar por escrito el misterio y el fantasma. La semantización de una realidad que se escapa, que fluye, como la vida, pues ambos padres originales ( $y$ no quiero dar paso a un desglose del principio de Totem y Tabú) murieron en favor de sus hijos, el padre y el tío materno del Ego. Desde esta perspectiva Lambert ejercita la imaginación y recuerda. Frente al sueño que hace olvidar, se levanta la memoria que permite evocar. Pero entonces Lambert de Wattrelos, como otros muchos harán después de él, percibió que en el origen de todo, más allá de esos peligrosos fantasmas, se levantaba una figura aún más enigmática, más lejana, más distante: la esposa del padre de su tío materno. ¿Qué se pensaba de ella? ¿Era una princesa?

34 Ch. Mela, La reine et le Graal, París 1984. 